\title{
Presence of Saprolegnia spp. (Oomycetes) in the Sivanamman Pond and its Characteristic Features
}

\author{
K M D Senathera Digamadulla ${ }^{1 *}$, K Sivashanthini ${ }^{1}$ and AC Thavaranjit ${ }^{2}$ \\ ${ }^{1}$ Department of Fisheries, University of Jaffna, Sri Lanka. \\ ${ }^{2}$ Department of Botany, University of Jaffna, Sri Lanka.
}

\begin{abstract}
Simultaneous improvisation in expertise and facilities in disease diagnosis have led to the identification of several previously unknown pathogens and diseased conditions. Saprolegniosis is one of the disease for which no known remedies were discovered yet. The current research was intended to study the presence and characterization of Saprolegnia spp. The study results hoped to be beneficial to many aspects of aquaculture and research on Saprolegniosis. Water sample was collected from Sivanamman pond (9 40'50.9'N and $80^{\circ} 01^{\prime} 43.6^{\prime}$ 'E). Saprolegnia spp. was isolated by baiting method under in vitro condition. Identification and characterization was carried out on cultural, vegetative and sexual characteristics featured by Saprolegnia spp. under microscopic observation. Isolate was identified as an aquatic fungus belongs to Saprolegnia spp. with respect to the sporulation from zoosporangium and sexual reproductive structures. The sexual morphologies were significant after a starvation (26 days) in the PDA. Eucarpic mycelium was transparent, vacuolated cytoplasm contained several nuclei and produced differential oogonium with oospores. The results of present study reveal the occurrence of Saprolegnia spp. in Jaffna urban ponds and evidently prove that the mold is administrable in PDA medium.
\end{abstract}

Keywords: Fish disease, Oomycetes, Saprolegniosis

\section{Introduction}

Diseases of aquaculture species were mainly caused by parasites and infectious pathogens. Studies on diseases have attracted the attention of veterinarians and the biologists from early days of aquaculture investigation. In the light of current development in science a number of prophylactic and curative measures have also been developed (Weena et al., 2005) and suggested. Although many chemicals have not been yet cleared for use in some countries, there are a number of diseases for which there were no known remedies yet, such as Saprolegniosis.

Saprolegniosis is an important fungal disease that is wide spread in all stages of the life cycle of fish (Hussein et al., 2001), caused by Genus Saprolegnia belongs to Class Oomycetes and commonly known as water moulds. Genus Saprolegnia in the family of Saprolegniacea is ubiquitous in water supplies and often causes

*Correspondence: sheandiga90@gmail.com 
losses due to saprolegniosis in fishes and range of other aquatic animals (Pillay and Kutty, 2005). Saprolegniosis infection contributes to heavy mortality among in fishes live in freshwater (Noga, 1996; Bruno and woods, 1994; Hussein and Hatai, 1999). In Asia, disease problems were considered to be of secondary importance where extensive farming was the main common practice. With the adoption of semi-intensive and intensive systems the mortalities has significantly increased (Pillay and Kutty, 2005). Saprolegnia spp. has been reported in waters of Japan, Philipines, Australia and throughout the South Asia (Blazer et al., 2002). Simultaneous improvisation in expertise and facilities in disease diagnosis have led to the identification of several previously unknown pathogens and diseased conditions. Consequently, greater efforts are now being made to diagnosis and control disease condition in the region.

In Sri Lanka it is considered to be a single largest cause of economic losses in aquaculture (Meyer, 1991) secondly to the bacterial disease. In Sri Lanka any information on this disease was not published but available in the technical records of Aquaculture Extension Units and hatcheries. In the past this problem was solved with extremely effective fungicide, Malachite Green (Pottinger and Day, 1992). The use of Malachite Green began in 1933 and it was one of the milestones in treatment history of fish against a range of parasites and pathogens (Foster and Woodbury, 1936; Meyer and Jorgenson, 1983).

Increasing investments in aquaculture and closer examinations of factors that contribute to the risks faced by an aquaculturist or pathologist, the concept of integrated health protection measures have been developing in recent years. The current research was intended to study the presence and characterization of Saprolegnia spp. The study results hoped to be beneficial to many aspects of aquaculture and research on Saprolegniosis.

\section{Materials and Methods \\ Collection of Sample}

Water samples were collected from Sivanamman pond (Urban pond), in the Jaffna peninsula (near Thirunelvely town). The period of sample collection was the dry season (May to October) of Sri Lanka. The mean water depth of the pond during the sampling period is $200 \pm 1 \mathrm{~cm}$. Samples were collected by sterilized trigger aided bottled sampler. Sample collection was done at the day time. Collected samples were brought to the laboratory as early as possible for the further examination.

\section{Isolation of Aquatic Fungi (Baiting Method)}

$15 \mathrm{~mL}$ of water sample was aseptically transferred in to a sterile petri dish by using a sterile pipette. Surface sterilized boiled seeds of rice were placed in the center of the petri dish. Petri dishes were incubated at room temperature $\left(32 \pm 5^{\circ} \mathrm{C}\right)$ for 3-5 days for the cultivation of aquatic fungi.

\section{Culturing of Fungi}

Potato Dextrose Agar medium (PDA) was prepared with the addition of the trace amount $(5$ $\mathrm{ppm}$ ) of Streptomycin. Medium was poured into sterile petri dishes under aseptic condition and allowed to set. A loopful of fungal growth on the boiled rice seed was taken by a sterile inoculation loop and aseptically transferred on the PDA medium by streaking in a zig- zag manner. Plates were incubated at room temperature for 3-5 days.

\section{Obtaining Pure Culture}

Pure culture of fungi was obtained by subsequent sub culturing technique. 


\section{Maintenance of Pure Culture}

PDA slants were prepared and a loop of pure culture was aseptically transferred on a slant by zig- zag streaking manner with a sterile inoculation loop. After the incubation of 3 days at room temperature these slant cultures were stored as stock cultures in a refrigerator at $10^{\circ} \mathrm{C}$ for future studies.

\section{Identification of Saprolegnia spp.}

Small portion of culture was taken by using a sterilized inoculation loop and placed on a clear slide and a drop of cotton blue was added. After a minute the mycelium was covered by coverslip, then gently pressed and observed under microscope. Identification was done by using cultural, vegetative and reproductive characteristics of fungi.

\section{Results}

\section{Characterization and Identification of} Saprolegnia spp.

Saprolegnia spp. is a saprophytic fungus which proliferates in a high $\mathrm{C}: \mathrm{N}$ condition. As a biological indicator of pollution, from the presence of Saprolegnia spp. we can determine whether the pond is deteriorated in condition or not. Preliminary screening by Baiting method (Vashishta, 2002) in the PDA (Potato Dextrose Agar) medium confirmed the presence of Saprolegnia spp., through the white colour cotton like mycelia (Plate 1and 2).

Serial culture is maintained to ensure the perfect isolation and also for the further studies. The well grown Saprolegnia spp. in the medium looks like cotton wool and it grows radially and spreads mycelia (Plate 1 and 2). Fungal is visible as white or gray patches of filamentous mycelium
(Bruno and Wood, 1994; Beakes et al., 1994) that radiates out in a circular, crescent-shaped or whorled pattern in PDA was observed under dissecting microscope (Weena et al., 2005). It produced a full growth of $9 \mathrm{~mm}$ diameter mycelia after $168 \mathrm{Hrs}$ (7 days). In the latent or lag period of three days the fungus did not influence the medium (Barbier, 1969). Then the onset growth was observed after 3-8 days and in the subsequent period maximum growth was extended from eight to thirty days (Kauffman, 1908).

Growing young mycelia on agar from serial cultured plate was teased and observed frequently under microscope (Plate 3). The vegetative thallus is tubular, non septate, multinucleate, variably branched (Weena et al., 2005) and with transparent envacuolated hypae (Plate 3, 4 and 5). The mycelium of the Saprolegnia spp. was coenocytic and branched. One of the vegetative phases, Rhizoids (intramatrical hyphae) anchor the mycelium to absorb the nutrition. Extramatrical hyphae were long hyphae grew out from the surface of the substratum into the medium and extend in all directions. They formed the visible portion of the mycelium and produced the reproductive organs. Next to the hyphal wall, the vacuolated cytoplasm was thin lining layer contained several nuclei and the mycelium was eucarpic (Plate 4 and 5) (Vashishta, 2002).

Active motile zoospores structures formed by sporulation were observed (plate 6 and 7). It takes place by means of pear-shaped, biflagellate zoospores (Plate 6 and 8) which are produced in long, cylindrical tapering zoosporangia (Plates 6 and 7), which is merely oval in shape (Fruit like) and carrying spores (Plate 7). 

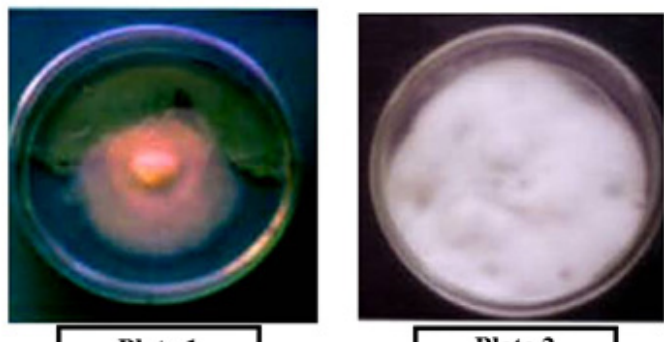

Plate 1

Plate 2

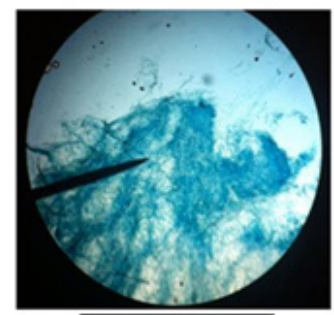

Plate 3

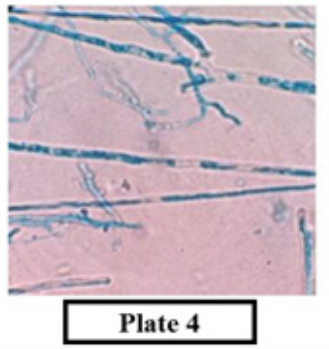

Plate 1: Saprolegnia spp in a control PDA disc method culture; Plate 2: Fully grown Saprolegnia spp in a control PDA disc method culture; Plate 3: Cluster of mycelia under X40 magnification; Plate 4: Single hypae under X100 magnification
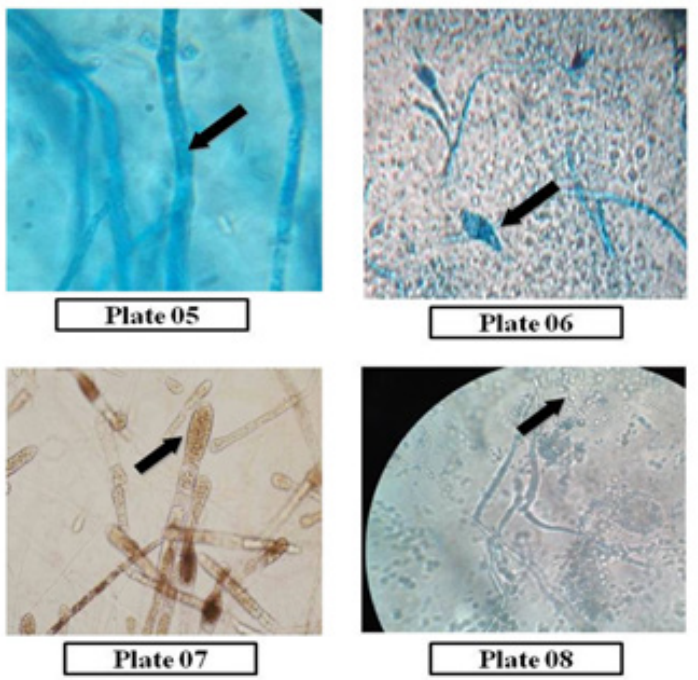

Plate 5: Poly nucleated cytoplasm of hypae under X400 magninifcation; Plate 6: Zoosporangium of Saprolegnia spp.; Plate 7: Unstained early stage Zoosporangium of Saprolegnia spp.; Plate 8: Zoospores of Saprolegnia spp. under X400 magnification. 
Zoospores were discharged one by one in rapid succession through an apical exit pore of sporangium (Plate 6), the zoosporangia developed or formed at the tip of somatic hyphae; which are not differentiated into sporangiospores.

The zoosporangia are only slightly greater in diameter than the hyphae bearing them. They are densely filled with protoplasm whereas the somatic hyphae are only lined with a thin layer of protoplasm. Zoosporangia are filiform, cylindrical, clavate, or irregular; terminal at first; renewed by internal proliferation. Enumeration of spores is difficult under X600 magnification. It is hard to make inoculum of asexual spores, due to their highly microscopic nature of the structure.

Willoughby (1978) described two vegetative characteristics of the Saprolegnia diclina -

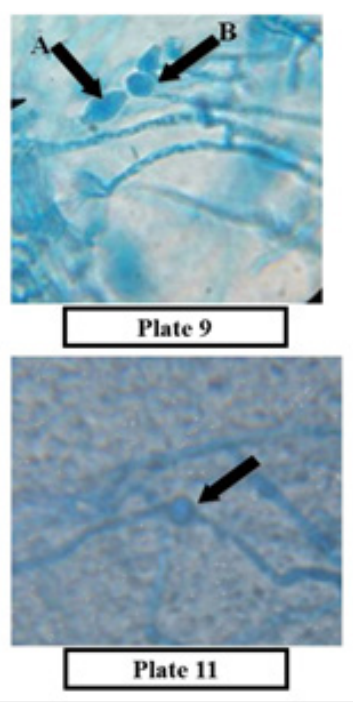

Saprolegnia parasitica complex. They were groups of long, hooked hairs on secondary zoospore cysts and indirect germination of secondary zoospore cysts.

Identification of different species of Saprolegnia spp. is difficult and can only be done by taxonomic analysis of the sexual structure combined with limited morphological characteristics of the organism. Based on the mode of biflagellate zoospore (Plate 8) release from zoosporangia, the isolate was identified as an aquatic fungus belongs to Saprolegnia spp.

In present study it was decided to use the term Saprolegnia spp. for all non-sexual isolates of Saprolegnia spp., as scientists recently have concluded that it is best to name all non-sexual isolates of genus Saprolegnia from fish as Saprolegnia spp. (Hughes 1994).

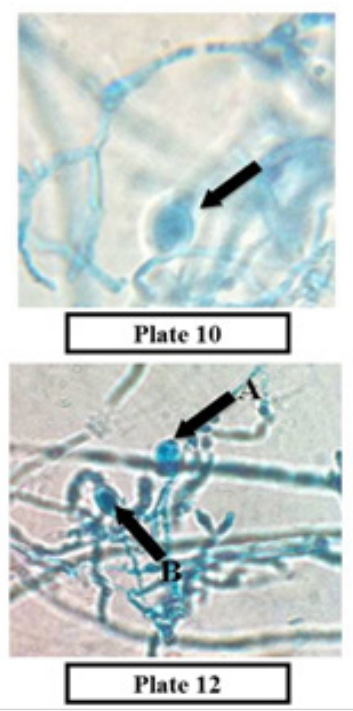

Plate 9: Oosporangium (a) and sporulation from oosporangium (b) of Saprolegnia spp.; Plate 10: Complex of oogonium and Antheridium under X600; Plate 11: Oosporangium (a) and sporulation from oosporangium (b) of Saprolegnia spp.; Plate 12: Complex of Oogonium and Antheridium under X600. 
Under microscope observations, Saprolegnia spp. had both sexual and asexual reproductive organs. Sexual reproductive organs are antheridium and oogonium, which were united for fertilization (Plate 9, 10,11 and 12). As the Saprolegnia spp. isolates commonly do not produce any sexual structures in the in vitro condition and cannot be identified at species (Hughes, 1994), and are therefore grouped in the generic classification as Saprolegnia spp.(Beakes et al., 1994; Pickering and Willoughby, 1982).

Oogonium and antheridium were observed at the tips of somatic hyphae. The oogonium is more or less spherical in structure with a thick wall. It is delimited from the supporting hypha (stalk) by a septum which is a solid plate. The mature oogonium (Plate 10,11, 12, 13 and 14) contained four to five naked, uninuclear, spherical oospheres or eggs. The egg is known as centric. The antheridia are borne on long or short, slender hyphae called the antheridiophores. The mature antheridium is an elongated, tubular, multinuclear structure delimited by a basal cross wall. It contains abundant protoplasm and is smaller than the oogonium. No sperms are organized (Plate 9 and 12).

Sexual reproduction involves the production of antheridium and oogonium gametangia, which unite for fertilization (Pickerning and Willoughby, 1982; Seymour, 1970).
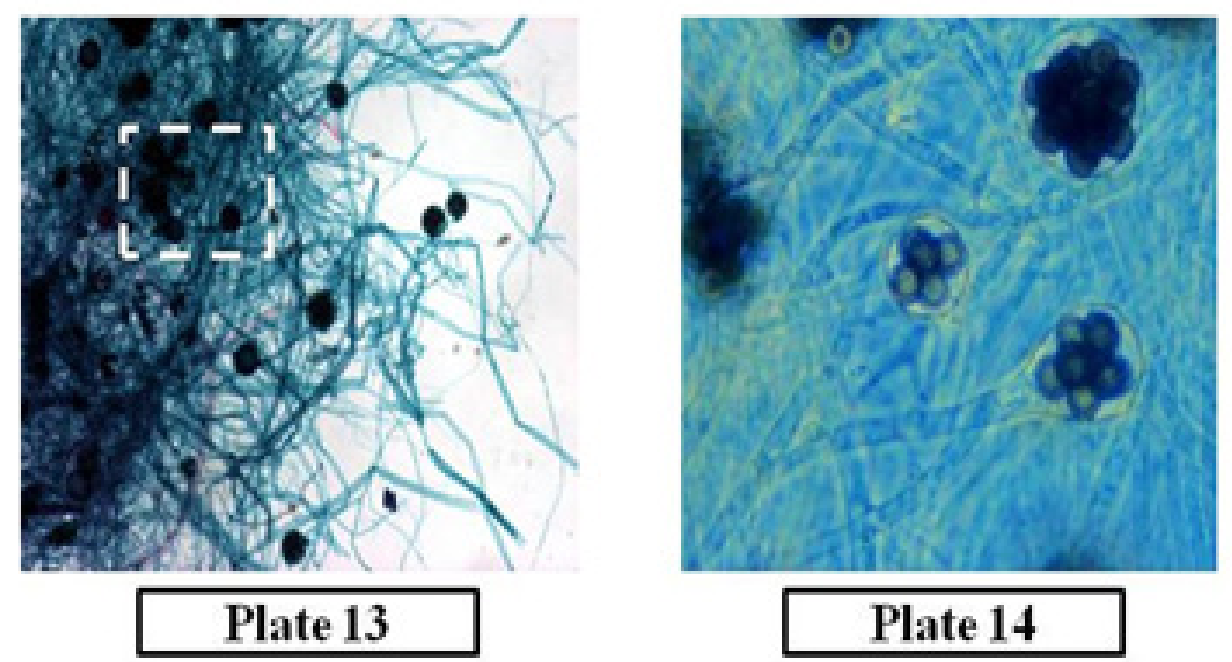

Plate 13: Oosporangium (a) and sporulation from Oosporangium (b) of Saprolegnia spp.; Plate 14: Complex of Oogonium and Antheridium under X600. 
Formed thalli were monoecious. Hyphae are stout or delicate, branched or unbranched, straight or flexuous, gradually tapering from base to apex; variable in length and diameter. Gemmae when present formed by segmentation of the hyphae; variable in size and shape; functioning as zoosporangia or oogonia or germinating by one or more slender hyphae. All the sexual morphologies were appeared after a starvation in the PDA; observations confirmed that presence of oogonia and antheridia after 26 days.

\section{Discussion}

Present study was done in the in vitro condition and it is the preliminary study on Saprolegnia spp. in Sri Lanka so far. Sri Lankan Literatures regarding current study were lacked. The preliminary isolation was succeeded and the results of the conducted experiments were evident to prove the presence of Saprolegnia spp. in the Jaffna freshwater bodies.

The fungus used in this study was isolated from the water sample collected from Sivanamman kovil pond. It is a urban pond, people live in the area pollute the pond through point and non-point sources. According to the reports of baiting method, there is an ample of room for the occurrence of Saprolegniosis in the pond and respectively in Jaffna. The screening study results will be beneficial to many aspects of aquaculture and research.

The water mold, Saprolegnia spp. is well known as a fungal parasite of fish. It may be responsible for rapid destruction of eggs or extensive external necrosis on adult fishes. These lesions, often carrying a free mass of fungal mycelium, have been recorded for over 250 years. A brief review of saprolegniosis in fish, however, reveals a startling lack of basic information on these obvious molds, and the disease they incite in their host animals. This gap in knowledge relates to several factors that bear on this research project. In the isolation and in vitro culture practices, maintenance of pure culture is so difficult; the inoculums blocks were always taken at $3 \mathrm{~cm}$ away from the center of the culture plates for subculturing and placed in the center of another new plate under aseptic condition. Bacteria are commonly found as contaminants with the Saprolegnia spp., due to that white colour cotton like mycelia which bleared into greyish colour. The occurrence of some association with bacteria and debris in nature was reported in previous studies (Bruno and Wood, 1994) and some bacteria may repel or are antagonistic to Saprolegnia spp. (Beakes et al., 1994; Peterson et al., 1994). Anti-bacterial agents like streptonmycin and amphicillin were incorporated with media during preparation (Mortada et al., 2001).

There has been a prolonged debate, dating from 1880 salmon plague in England, whether Saprolegnia spp. acts as a primary or secondary disease agent (Neish and Hughes, 1980; Hatai and Hoshiai, 1994). This argument gradually received less energy following the discovery and widespread use of the effective chemical control agent, Malachite green. The situation is now changing. Malachite green is recognized as a toxic compound and is essentially banned in the United States. Formalin, the alternative choice, has its own problems (e.g. potential toxicity to handlers; cost of container disposal).

On the fungal side, there are relatively few studies of Saprolegnia spp. in fish. Tiffney (1939); Neish (1977); Willoughby (1978); and Hatai and Hoshiai (1994) pointed out the existence of special strains of the fungus that parasitize different types of fishes. These strains 
are distinct from the saprophytic water molds that may be isolated from almost all ponds, streams and lakes. The parasitic strains can be repeatedly isolated from salnonid fish, and both Tiffney (1939) and Neish (1977) have produced experimental data indicating that saprolegnian strains may attack uninjured salmon. These mycological studies also point out the difficulties faced in studying Saprolegnia spp. in fish. This water mold is a member of the Oomycetes, a distinct group of fungi that is, now commonly, associated with the Protista and not the true fungi (Margulis et al., 1990).

Although these organisms, with their biflagellate spores and unusual cell walls, are obviously different from other molds, mycologists have struggled to find adequate criteria to classify the different taxa within the class, oomycetes, itself. Taxonomic differentiation, from the ordinal to the sub-specific level, is difficult and under constant revision (Dick, 1965).

In the case of the Saprolegniaceae, the family that includes most fish pathogens, the generic distinctions are mainly based on the nature of asexual reproduction, which we now know may be influenced by a variety of environmental factors such as temperature, $\mathrm{O}_{2}, \mathrm{CO}_{2}$ and light (Salvin, 1941; Scott, 1964).

Identification at the species level, in contrast, relies on the morphology of the sexual phase. Unfortunately, watermolds isolated from salmon and other aquatic animals typically lack a sexual phase. Coker (1923), an early student of these fungi, pragmatically decided to create a special taxon, Saprolegnia parasitica for these asexual, unidentifiable water molds. Subsequent workers found occasional sex organs in their isolates, especially when the latter were cultured under special conditions (Kanouse, 1932).
Contemporary reviews on this problem (Hughes, 1994; Neish and Hughes, 1980; Seymour, 1970) have forcibly pointed out that we are still suffering from a dualistic view of the causal agent of saprolegniasis in fish. Neish (1977) and Willoughby (1978) responded to this problem by studying multiple characters of numerous isolates from parasitized salmon. Their results established the existence of different biotypes, showing differing patterns of specificity and pathogenicity toward the host.

With reference to the in vitro (in laboratory conditions) observations have provided valid evident to prove that the isolate is Saprolegnia spp. This was due partly to different opinions among scientists regarding the naming of pathogenic Saprolegnia species, and partly to a recent conclusion by scientists that all nonsexual isolates of Saprolegnia from fish should be named Saprolegnia spp. (Hughes 1994). In present study the white, fluffy colonies on agar, isolated from the water sample was evidently Saprolegnia spp. because of the similar appearance to the colonies earlier identified to be Saprolegnia spp. The pathogenic fungus found in the water is the same fungus which also infected the fishes and amphibians in the pond.

Identification of different species of Saprolegnia spp. is difficult and can only be done by taxonomic analysis of the sexual structure combined with limited morphological characteristics of the organism. Currently DNA fingerprinting is becoming an important technique for identifying of Saprolegnia spp. isolates (Whisler, 1996).

In vitro culture of Saprolegnia species practices' (Shiow ying chong, 1973; Osman et al., 2008) have been done with sterilized hemp seed (Miller et al., 1969), Sabaroud's dextrose agar (SDA, difco agar) (Osman et al, 2008; Das et al., 2012), 
Potato Dextrose Agar (PDA), Glucose and Peptone (GPA), Glucose Yeast extract (GYE) and other Chemically defined media (Shiow ying chong, 1973).

Shiow ying chong found that PDAas a moderated media for the laboratory studies. In the current experiment Saprolegnia spp. produces sporangia on the $4^{\text {th }}$ day and onwards. Oogonium and atheridium any sexual organs were not present in the fungi even in his 7 day observation. PDA is a fair media for the studies on sexual structures, gemmae and hyphal thickness of Saprolegnia spp. Growth in PDA was obvious from $48 \mathrm{hrs}$ of incubation, in $10^{\circ} \mathrm{C}$ Oogonum was produced at the end of 1 week incubation on the PDA. Shiow ying chong (1973) found that Saprolegnia spp. starts to grow in the PDA from the $2^{\text {nd }}$ day of incubation and it produces sporangia on the $4^{\text {th }}$ day and onwards. After $7^{\text {th }}$ day neither oogonium nor antheridium was observed. But in our study after huge starvation observations confirmed that presence of oogonia and antheridia in the $26^{\text {th }}$ day.

\section{Conclusion}

The present study on parasitic isolate of Saprolegnia spp. from Sivanamman kovil pond water sample was undertaken to provide data on cultivation under controlled laboratory conditions, is an effort to broaden our knowledge of the effect of environmental factors on the growth of the fungus and to assess the relationships of these results to the role of the test fungus as a fish parasite.

It is hoped that this work will stimulate more interest in this type of research, demonstrate the desirability of careful testing of the media used and elicit a better understanding of the variability introduced in experimental studies of parasitic Saprolegniaceae through choice of culture media and treatments.
With reference to the result, presence of Saprolegnia spp. is undoubtedly evident for the poor managed irrigation system of the urban pond (Sivanamman kovil pond). The tolerance limit is more similar in the group of isolated Saprolegnia spp., but variations are obvious due to the difference in strain.

\section{References}

Barbie, J. (1969). Ann. Sci. Nat. Bot, 12: 473-564.

Beakes, G.W., Wood, S.E. and Burr, W.A. (1994). A review - In salmon Saprolegniasis. G. J. Mueller (ed.), 33 - 66.

Blazer, V.S., Lilley, J. H., Schill, W.B., Kiryu, Y., Densmore, C.L., Panyawachira, V. and Chinabut, S. (2002). J Aquatic Animal Health, 14: 1-10.

Bruno, D.W. and Wood, B.P. (1994). In Fish Diseases and Disorders, Volume 3, Viral, Bacterial and Fungal Infections. Edited by P.T.K. Woo and D.W. Bruno. CABI Publishing, 599-659.

Coker, A.C. (1923). The saprolegniaceae, with notes on other water molds. University of north Carolina Press, 201 pp.

Das, S.K., Murmu, K., Das, A., Shakuntala, I., Das, R.K., Ngachan, S. V., Majhi, S.K. (2012). J. Environ. Biol., 33: 545-549.

Dick, M.W. (1965). Mycologica, 57: 828-830.

Foster, F.J. and Woodbury, L. (1936). The progressive fish-culturist, 3: 7-9.

Hatai, K. and Hoshiai, G.I. (1994). In Salmon Saprolegniasis. Edited by G. J. Mueller, 8798.

Hughes, G.C. (1994). In Salmon Saprolegniasis. Edited by G. J. Mueller, 3 - 32. 
Hussein, M., Hatai, K. and Nomura, T. (2001). J. Wild Dis., 37(1): 204- 207.

Hussein, M.M.A. and Hatai, K. (2002). Fish. Sci., 68: 1067-1072.

Hussein, M.M.A. and Hatai. V. (1999). Mycoscience, 40: 385-389.

Kanouse, B.B. (1932). Mycologia, 24(5): 431455.

Kauffman, C.H. (1908). Annls. Bot. 22: 361-388.

Margulis, L., Corliss, J. O., Melkonian, M. and Chapman, D.J. (1990). A guide to the algae, ciliates, foraminfera, sporozoa, water moulds, slime moulds and the other protoctists, Jones and Bartlett publishers.

Meyer, F.P. (1991). J. Anim. Sci. 69: 4201-4208.

Meyer, F. and Jorgensen, T. (1983). Am. Fish. Soc. 112(6): 818 .

Miller E., Charles., Ristanovic. and Bosiljka. (1969). The Ohio Journal of Science, 69(2): 105-109.

Mortada, M.A., Hussein., Hatai, K. and Nomura, T. (2001). Journal of Wildlife Diseases, 37(1): 204-207.

Neish, G.A. (1977). Journal of fish biology 10: 513-522.

Neish, G.A. and Hughes, G.C. (1980). Diseases of fishes, $159 \mathrm{pp}$.

Noga, E.J. (1996) Fish Disease Diagnosis and Treatment, $367 \mathrm{pp}$.
Osman, H.M., Solman, W.E., Noor, E.D. and Laila, A. (2008). Mohamed, Global veterinaria, 2(1).

Pickering, A.D. and Willoughby, L.G. (1982). Microbial Diseases of Fish, Edited by R.J. Roberts. Academic Press, 271-297.

Pillay, T.V.R. and Kutty, M.N. (2005). Aquaculture principles and practices. Blackwell Publishing. Ltd. 231 pp.

Pottinger, T.G. and Pickering, A.D. (1992). J. Fish Biol. 41: 435-447.

Salvin, S.B. (1941). Mycologia, 33: 592-600

Scott, W.W. (1964). Indust. Microbial. 5: 109123.

Seymour, R.L. (1970). Nova Hedwigia, 19: $1-124$.

Shiow ying chong, (1973). Msc Thesis.

Tiffney, W.N. (1939). Mycologia, 5(1): 134-151.

Vashishta, B.R. (2002). Botany for degree students part II, Chand, S. \& company ltd.

Weena, K., Panarat, P., Jirasak, T. and Hatai, K. (2005). J. Sci. Res. Chula. Univ. 30(2): 123-130.

Willoughby, L.G. (1978). J Fish Dis.1: 51-67.

Whisler, H.C. (1996). Pathogenic in Chinook Salmon (Final Report), DEAC7990BP02836, US Department of Energy, Washington, D.C., 43 pp. 